\title{
Mannitol and renal graft injury in patients undergoing deceased donor renal transplantation - a randomized controlled clinical trial
}

Christian Reiterer ${ }^{1 \dagger}$, Karin Hu ${ }^{2+}$, Samir Sljivic ${ }^{1}$, Markus Falkner von Sonnenburg ${ }^{1}$, Edith Fleischmann ${ }^{1 *}$, Alexander Kainz ${ }^{2}$ and Barbara Kabon ${ }^{1}$

\begin{abstract}
Background: Ischaemia/reperfusion (I/R) injury is associated with renal tissue damage during deceased donor renal transplantation. The effect of mannitol to reduce I/R injury during graft reperfusion in renal transplant recipients is based on weak evidence. We evaluated the effect of mannitol to reduce renal graft injury represented by 16 serum biomarkers, which are indicators for different important pathophysiological pathways. Our primary outcome were differences in biomarker concentrations between the mannitol and the placebo group $24 \mathrm{~h}$ after graft reperfusion. Additionally, we performed a linear mixed linear model to account biomarker concentrations before renal transplantation.
\end{abstract}

Methods: Thirty-four patients undergoing deceased donor renal transplantation were randomly assigned to receive either $20 \%$ mannitol or $0.9 \% \mathrm{NaCl}$ placebo solution before, during, and after graft reperfusion. Sixteen serum biomarkers (MMP1, CHI3L1, CCL2, MMP8, HGF, GH, FGF23, Tie2, VCAM1, TNFR1, IGFBP7, IL18, NGAL, Endostatin, CystC, KIM1) were measured preoperatively and $24 \mathrm{~h}$ after graft reperfusion using Luminex assays and ELISA.

Results: Sixteen patients in each group were analysed. Tie2 differed $24 \mathrm{~h}$ after graft reperfusion between both groups $(p=0.011)$. Change of log2 transformed concentration levels over time differed significantly in four biomarkers (VCAM1,Endostatin, KIM1, GH; $p=0.007 ; p=0.013 ; p=0.004 ; p=0.033$; respectively) out of 16 between both groups.

Conclusion: This study showed no effect of mannitol on I/R injury in patients undergoing deceased renal transplantation. Thus, we do not support the routinely use of mannitol to attenuate I/R injury.

Trial registration: NCT02705573. Registered on 10th March 2016.

Keywords: Mannitol, Renal transplantation, I/R injury, Renoprotection, Biology-derived biomarker

\footnotetext{
* Correspondence: edith.fleischmann@meduniwien.ac.at

${ }^{+}$Christian Reiterer and Karin Hu contributed equally to this work.

${ }^{1}$ Department of Anaesthesia, Intensive Care Medicine and Pain Medicine,

Medical University of Vienna, Spitalgasse 23, 1090 Vienna, Austria

Full list of author information is available at the end of the article
}

(c) The Author(s). 2020 Open Access This article is licensed under a Creative Commons Attribution 4.0 International License, which permits use, sharing, adaptation, distribution and reproduction in any medium or format, as long as you give appropriate credit to the original author(s) and the source, provide a link to the Creative Commons licence, and indicate if changes were made. The images or other third party material in this article are included in the article's Creative Commons licence, unless indicated otherwise in a credit line to the material. If material is not included in the article's Creative Commons licence and your intended use is not permitted by statutory regulation or exceeds the permitted use, you will need to obtain permission directly from the copyright holder. To view a copy of this licence, visit http://creativecommons.org/licenses/by/4.0/ The Creative Commons Public Domain Dedication waiver (http://creativecommons.org/publicdomain/zero/1.0/) applies to the data made available in this article, unless otherwise stated in a credit line to the data. 


\section{Background}

Renal transplantation is the treatment of choice for patients with end-stage-renal disease [1, 2]. Renal ischaemia and reperfusion $(\mathrm{I} / \mathrm{R})$ injury is one of the leading causes mediating acute kidney injury (AKI) in the native as well as in the transplanted kidney [3]. Re-oxygenation after ischaemia results in tissue injury due to apoptosis and necrosis, and activation of inflammatory pathways triggering innate immune responses [4].

Mannitol, an osmotic diuretic, is routinely used to improve renal function after deceased donor renal transplantation [5]. It increases renal blood flow, supposedly attenuates $I / R$ injury during graft reperfusion and acts as a free radical scavenger [6]. Additionally, it promotes the release of prostaglandins in the kidney leading to vasodilatation and consequently to an increased urine flow in the renal tubulars [7]. However, these beneficial effects are only based on weak evidence and the renoprotective potency of mannitol during renal transplantation is still lacking.

Estimated glomerular filtration rate (eGFR) after transplantation based on serum creatinine $(\mathrm{sCr})$ is mainly used for the clinical assessment of renal function. Even though, measurement of $\mathrm{sCr}$ is still the state of the art to estimate renal function, the sensitivity is low for detecting AKI of biopsy proven tubular injury $[8,9]$. Therefore, in the last decade a major focus of research was to detect new molecular biomarkers (BM) involved in disease relevant pathophysiological pathways.

In the chronic disease, BM were identified following a systems biology approach, which is based on a silico-derived molecular model of diabetic kidney disease. A parsimonious set of BM covering multiple relevant pathways was validated in a large group of patients with type II diabetes and was able to improve the predictive power for eGFR loss on top of clinical covariates [10,11].

Similarly, promising BM for AKI, delayed graft function and renal transplant outcome were identified [9, 12-16]. Consequently, we tested the intraoperative use of mannitol on a set of 16 BM representing different molecular processes involved in ischaemic kidney injury, inflammation and tubular damage.

\section{Methods}

This prospective double-blinded, randomized trial was performed at the Department of Anaesthesia, Intensive Care Medicine and Pain Medicine and the Department of Nephrology and Dialysis, Medical University of Vienna, Vienna, Austria. The trial was approved by the local ethics committee of the Medical University of Vienna in 2014 (Chairman: J. Zezula, MD) (EK 2021/2014) and was registered at ClinicalTrials.gov (NCT02705573) and EudraCT (2014-005391-29) and conducted according to the Declaration of Helsinki and Good Clinical Practice.
Written informed consent was obtained from all patients. Patients with end-stage renal disease between 18 and 80 years of age undergoing deceased donor renal transplantation were included. Exclusion criterion was a known allergy to mannitol. All patients were hemodialysed shortly before renal transplantation.

Non-heart-beating donors were not included. Hypothermic machine perfusion of deceased donor kidneys was not performed.

\section{Randomization}

Patient allocated to the mannitol group received a $20 \%$ mannitol solution in a dose of $5 \mathrm{~mL} / \mathrm{kg}$ bodyweight (BW) (Concentration: $5 \mathrm{~mL}=1 \mathrm{~g}$ ) The placebo group received $0.9 \% \mathrm{NaCl}$ solution in a dose of $5 \mathrm{~mL} / \mathrm{kg}$ BW. The maximum dose of the study medication was restricted to $500 \mathrm{~mL}$.

A bolus of $100 \mathrm{~mL}$ of the study solution was administered shortly before graft reperfusion. The remaining study solution was infused till the end of surgery. Randomization and blinding of the study drug were performed by the pharmacy. The patient, the attending anesthesiologist, and the research team were unaware of the group allocation.

Randomization sequence was created by an investigator with no clinical involvement in the trial using simple randomization procedures.

\section{Protocol}

Anesthesia was induced with $2-3 \mu \mathrm{g} \mathrm{kg}-1$ BW fentanyl and $2-3 \mathrm{mg} \mathrm{kg}^{-1}$ BW propofol. Muscle relaxation was performed at the discretion of the attending anesthesiologist. Narcotrend guided anesthesia was maintained with sevoflurane in 30\% oxygen. Additional fentanyl was administered according to patient's requirements. We kept endtidal $\mathrm{CO}_{2}$ at near $4.7 \mathrm{kPa}$. Non-invasive blood pressure was measured in 5-min intervals. Normothermia was maintained with forced-air warming. According to clinical standards, all patients received a central venous line. Central venous blood gas samples were obtained hourly.

Fluid administration was esophageal Doppler guided (Cardio Q, Deltex Medical, Chichester, UK) according to a previous published algorithm [17]. A balanced crystalloid solution (Elomel isoton; Fresenius Kabi, Austria) was used for intraoperative fluid replacement therapy. All patients received a baseline infusion rate of $2 \mathrm{~mL}$ $\mathrm{kgBW}^{-1} \mathrm{~h}^{1}$. We performed intraoperative goal-directed fluid management using esophageal Doppler monitoring (CardioQ; Deletex Medical, Chicester, UK). Our fluid management was based on the algorithm published by the Anesthesia Working Group of the 'Enhanced Recovery after Surgery (ERAS) Society [17] and slightly modified. 
We placed the esophageal Doppler probe after induction of anesthesia. After the characteristic Doppler signal was displayed, a fluid challenge of $250 \mathrm{~mL}$ was administered to assess stroke volume (SV) response. If the SV increased > $10 \%$ (i.e. fluid responder), a further fluid bolus was administered. This was repeated as often as no further increase of more than $10 \%$ in SV was detected. In fluid nonresponders we treated coexisting hypotensive episodes, which were defined by a mean arterial pressure (MAP) < $70 \mathrm{mmHg}$ in normotensive and $<80 \mathrm{mmHg}$ in hypertensive patients, with vasopressor titration at the discretion of the attending anesthesiologist.

Hemodynamic parameters were re-evaluated at least every $15 \mathrm{~min}$ (or more frequently in case of significant hemodynamic changes, e.g. blood loss). When SV dropped more than $10 \%$, we administered a further fluid bolus according to the above described algorithm.

Blood units were given as necessary. Transfusion trigger was a hemoglobin concentration of $7.0 \mathrm{mg} \mathrm{dL}^{-1}$. However, if there was any clinical sign of organ hypoxemia (e.g. lactic acidosis) blood units were given earlier at the discretion of the attending anesthesiologist.

During the study period the use of diuretics was not allowed.

\section{Blood samples}

Blood samples for BM measurements were taken in $\mathrm{Z}$ Serum Separator Clot Activator vacutainers (Greiner Bio-One, Austria). Blood was drawn shortly before induction of anesthesia and $24 \mathrm{~h}$ after graft reperfusion. Samples were allowed to clot for $30 \mathrm{~min}$ at room temperature before centrifuging at $1000 \mathrm{~g}$ for $10 \mathrm{~min}$ at room temperature. Serum was removed and stored at $80{ }^{\circ} \mathrm{C}$ until further processing.

\section{Measurements}

Demographic data, comorbidities, renal-replacement therapy, residual urinary output, long-term medication and preoperative laboratory values were obtained from patient's medical records. Renal transplant specific data including arterial and venous vascular clamp times, intraoperative fluid requirements, blood loss, hemodynamic parameters and anesthesia specific management were recorded.

Donor and organ specific information including age, sex, laboratory values, diuresis, catecholamine support and cold and warm ischaemia time were provided by Eurotransplant.

Potassium, urinary output, creatinine, BUN and GFR were measured $24 \mathrm{~h}$ after graft reperfusion.

\section{Luminex serum measurements}

Measurements of serum samples were carried out using three panels: Luminex 3-plex, Luminex 12-plex and
ELISA. Quantikine ELISAs for human serum TIM-1/ KIM-1/HAVCR (catalog no. DSKM100, R\&D Systems, Minneapolis, MN) were used for measurement of KIM1 serum concentrations. Assays were processed according to the procedure guidelines provided. The optical density of each plate was measured within $30 \mathrm{~min}$ using a TriStar [2] LB 942 Modular Multimode Microplate Reader (Berthold Technologies, Bad Wildbad, Germany) set to $450 \mathrm{~nm}$ and wavelength correction set to $570 \mathrm{~nm}$. The standard curve was generated using MikroWin2010 v5.21 software with a four-parameter logistic (4-PL) curve fit.

Three markers (Endostatin, CystC and NGAL) were measured using a Human Premixed Multi-Analyte Kit (catalog no.LXSAHM-03; R\&D Systems). Samples were diluted 1:50 using Calibrator Diluent RD6-52 provided in the assay kit. The remaining twelve BM (MMP1, MMP8, HGF, GH, CHI3L1, TIE2, TNFR1, VCAM1, CCL2, FGF23, IL18 and IGFBP7) were measured using a Human Premixed Multi-Analyte Kit (catalog no.LXSAHM-12; R\&D Systems) and a samples dilution of 1:2. Both assays were processed according to assay procedure provided by the manufacturer and measured on a Luminex 200 (Luminex Corporation, Austin, TX) with xPONENT software (version 3.1.971.0) set according to assay instructions.

Calibration and verification of the Luminex 200 was preformed once a week using Luminex 200 Performance Verification Kit (catalog no. 40-276, Merck Millipore, Billerica, MA) and Calibration Kit (catalog no. 40-275, Merck Millipore).

As no commercial quality controls (QC) were available for multiplex assays, Pooled Normal Human Plasma K3 EDTA (catalog no. IPLA-N-100 ml-K3 EDTA, Innovative Research, Novi, MI) was spiked with recombinant proteins (R\&D Systems) and diluted to different concentrations to act as low, medium and high QC samples for the Luminex panel and the KIM1 ELISA. All samples were measured as two technical replicates. If replicate measurements display a coefficient of variation over $12 \%$, the sample was remeasured. In addition, at least $10 \%$ of all samples were remeasured on a different plate to follow FDA and EMA guidelines which recommends incurred sample reanalysis with percentage difference between these samples below $20 \%$. More than $66 \%$ of incurred sample reanalysis fulfilled this requirement and are therefore in concordance with FDA and EMA guidelines. Values out of quantifiable range were set to 0.5 and 1.5 times lower and upper quantification limits, respectively.

\section{Statistical analysis}

Statistical analysis was performed using IBM SPSS Statistics (Version 25) and SAS 9.4 (Cary, NC). Normal 
distribution of the data was assessed with KolmogorovSmirnov test. Normally distributed data were presented as mean (standard deviation); not normally distributed data were given as median and percentile. Chi-square test was accomplished for comparing categorical variables. Interval variables between groups prior to transplantation were compared using a Mann-Whitney-Utest or a Student's t-test. Post transplantation a mixed linear model adjusted for donor kidney pairs was used to assess our primary outcome: differences in serum BM concentrations between both study groups $24 \mathrm{~h}$ after graft reperfusion. Additionally, in order to take preoperative $\mathrm{BM}$ concentrations into account another mixed linear model for concentration changes over time for each of the sixteen biomarkers was performed. Concentrations were standardised for each group and biomarker ( mean $=0$, standard deviation $=1$ ) to be able to compare the different models. In the model the dependent variable was the standardised concentration. Independent variables were treatment group and time point of measurement and their interaction. Additionally, we used the intercept and slope as random effects. (online Supplement).

A $p$-value $<0.05$ was considered as statistically significant.

\section{Sample size consideration}

Based on previous BM concentration measurements the standard deviation of the $\log 2$ transformed values in median (1st, 3rd quartile) is 0.86 (0.51.06). Therefore, in order to detect an effect size of 0.86 with a power of $80 \%$ using a two-sample t-test 17 patients in each study group were estimated to be sufficient to detect an significant difference in at leaset $50 \%$ of all $\mathrm{BM}$.

\section{Results}

In total 34 patients with end-stage renal disease undergoing deceased donor renal transplantation were enrolled between January 2018 and July 2018. Seventeen patients received mannitol and 17 patients received placebo (Fig. 1). One patient in the mannitol group deceased within $24 \mathrm{~h}$ after transplantation; therefore, no follow-up measurement was available. Another patient from the placebo group was lost to follow up due to missing samples. Both patients were excluded from the analysis. Demographic and morphometric data are summarised in Table 1. Donor specific characteristics are available in the online supplement are shown in Table 2.

Intraoperative characteristics including duration of anesthesia and surgery, fluid and hemodynamic data, anesthetic variables and central venous blood gas variables are shown in Table 3.
Routine parameters measured $24 \mathrm{~h}$ after graft reperfusion including potassium, urinary output, creatinine, BUN and GFR were compared between the two groups; none of those parameters displayed a significant difference (Table 4).

Concentration levels for all 16 BM before transplantation and $24 \mathrm{~h}$ after graft reperfusion grouped by treatment are illustrated in Fig. 2. Out of the 16 BM only Tie2 showed significant differences in concentration between the placebo group and the mannitol group $24 \mathrm{~h}$ after graft reperfusion $(p=0.011)$ (Table 5).

In order to take BM concentrations before transplantation into account, linear mixed models were applied for changes in BM concentrations pre transplantation and $24 \mathrm{~h}$ after graft reperfusion. Change of $\log 2$ transformed concentration levels over time differed significantly between the groups in four out of 16 biomarkers only (online Supplement, eAppendix 1, Table S1). In the mannitol group there was a higher increase of VCAM1 than the placebo group $(p=0.007)$. On the contrary, KIM1 increased significantly less in patients receiving mannitol as compared to those receiving placebo $(p=0.004)$. Endostatin and $\mathrm{GH}$ concentrations decreased significantly less in the mannitol group as compared to the placebo groups $(p=0.013$ and $p=0.033$, respectively).

\section{Discussion}

This study tested the efficiency of mannitol to reduce I/ $\mathrm{R}$ injury during kidney transplantations. eGFR is the standard clinical parameter to evaluate kidney function but lacks sensitivity for small changes in the filtration rate and is not able to reflect pathophysiological processes [18]. Therefore, we used a set of 16 serum BM representing different pathways involved in ischaemic injury and inflammation in patients with end-stage renal disease undergoing deceased donor renal transplantation.

Although mannitol has been used for over 30 years in clinical practice, there is only weak evidence of its beneficial effects [19]. Renoprotection e.g. superoxide radical scavenging, increased renal blood flow and/or less tubular necrosis were mostly found based on preclinical animal studies [20]. Specifically, data for the renoprotective potency during renal transplantation are still lacking. Data from clinical studies, mostly performed in 1980's revealed that mannitol reduced the incidence of acute tubular necrosis and decreased the number of dialysis required after transplantation. However no beneficial long-term effect could be observed in those studies [21-23].

A retrospective analysis based on an e-survey in 2011 showed that the use of diuretics during renal transplantation does not improve renal graft survival [24]. 


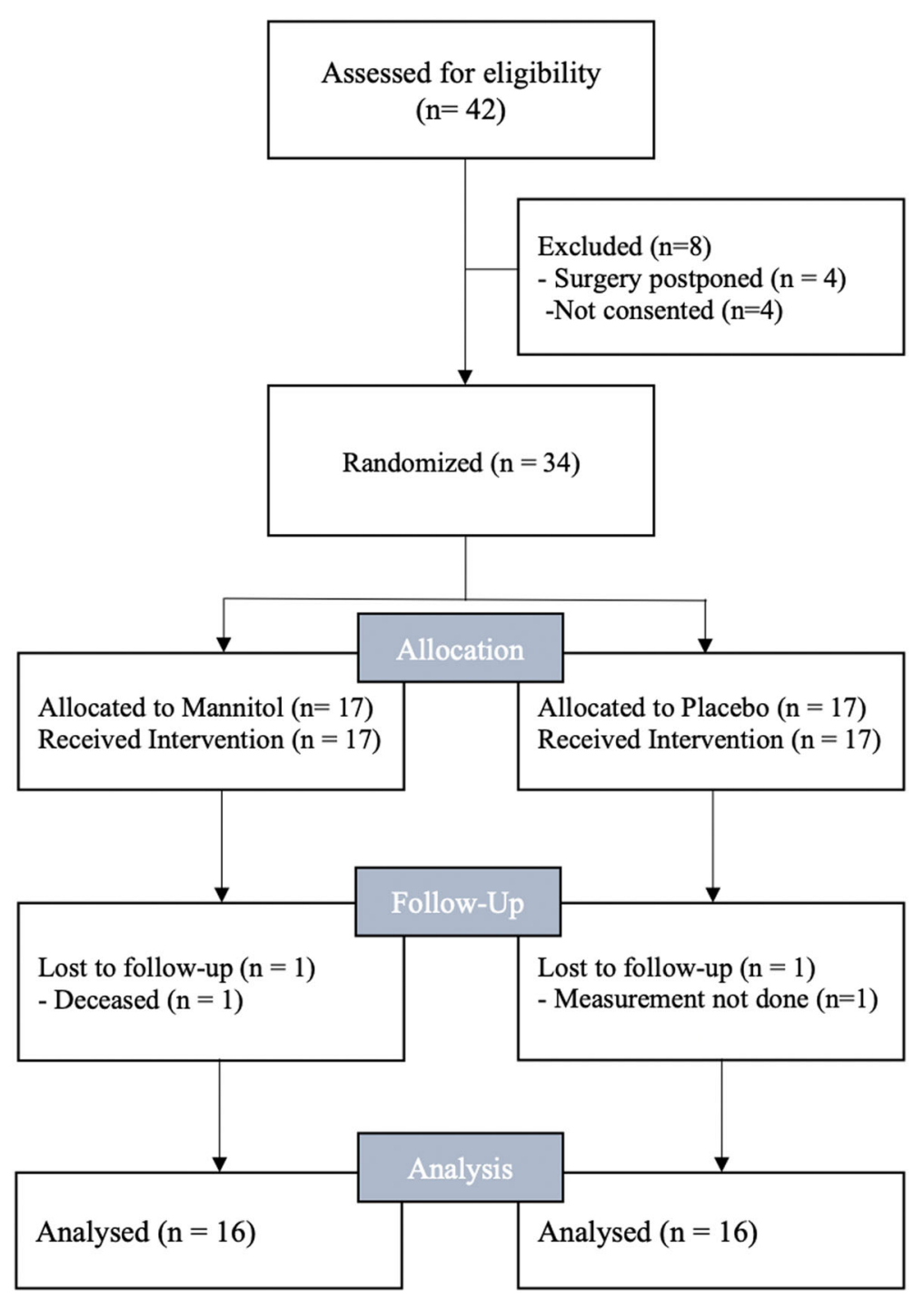

Fig. 1 CONSORT 2010 patients flow chart

Although, of the lack of of high quality studies mannitol is still routinely used in some high-volume transplantation centres throughout renal transplantation [5].

It seems unlikely that mannitol affects long-term graft function; we thus focused on the immediate postoperative period. eGFR is still considered to be the best clinical marker to predict renal graft function. Direct measurements, however, are mostly infeasible; rather equitation based on demographic parameters, which's accuracy to reflect real renal function in kidney transplant patients are limited [25], are used to estimate eGFR. Therefore, we measured a panel of promising $\mathrm{BM}$ to assess the renoprotective effect of mannitol.

We expected to see effects of mannitol reflected in the BM profile of the study patients. However, out of 16 BM only Tie2 was significantly different between the mannitol and the placebo group $24 \mathrm{~h}$ after transplantation. If $\mathrm{BM}$ concentrations before transplantation are taken into account only four BM (KIM1, Endostatin, GH and VCAM1) showed significant different changes in concentration over time.

The Angiopoietin(Ang)/Tie2 system is an important regulator for vessel stabilization and destabilization, and further to cope with injuries caused by ischemia and inflammation through binding of Ang1 to Tie2 as well as interactions of Ang2 as a context-dependent Tie2 antagonist. Shedding of Tie2 due to proteolytic cleavage occure upon various stimuli such as vascular endothelial growth factor (VEGF) and result in blocking of downstream signaling as soluble Tie2 acts as a competitive ligand for Ang1 and Ang2 [26]. A higher sTie serum level has been seen in serveral clinical conditions such as 
Table 1 Patient characteristics and preoperative data

\begin{tabular}{|c|c|c|c|c|c|}
\hline \multirow[b]{2}{*}{ Age, yrs } & \multicolumn{2}{|c|}{$\begin{array}{l}\text { Mannitol } \\
(n=16)\end{array}$} & \multicolumn{2}{|c|}{$\begin{array}{l}\text { Placebo } \\
(n=16)\end{array}$} & \multirow{2}{*}{$\frac{p-\text { Value }}{0.10}$} \\
\hline & 62 & {$[57,71]$} & 53 & {$[45,68]$} & \\
\hline Height, cm & 167 & \pm 10 & 170 & \pm 15 & 0.58 \\
\hline Weight, kg & 74 & \pm 17 & 78 & \pm 17 & 0.67 \\
\hline Gender, no. (\%) & & & & & 0.64 \\
\hline Men & 9 & (56) & 9 & (56) & \\
\hline Women & 7 & (44) & 7 & (44) & \\
\hline \multicolumn{6}{|l|}{ Comorbidities, no. (\%) } \\
\hline Hypertension & 15 & (94) & 15 & (94) & 1.00 \\
\hline Diabetes & 5 & (31) & 1 & (6) & 0.13 \\
\hline Insulin use & 4 & (25) & 1 & (6) & \\
\hline Non-Insulin use & 1 & (6) & 0 & (0) & \\
\hline Pulmonary & 2 & (13) & 5 & (31) & 0.39 \\
\hline Chronic Intermit. Dialysis, no. (\%) & 11 & (69) & 13 & $(82)$ & 0.70 \\
\hline Peritoneal Dialysis, no. (\%) & 5 & (31) & 3 & (19) & 0.70 \\
\hline GFR, $m L \min ^{-1} 1.73 \mathrm{~m}^{-2}$ & 9.34 & $(2.7)$ & 10.4 & $(3.4)$ & 0.36 \\
\hline Residual Urine Output ( $m L 24 h^{-1}$ ) & 500 & {$[0,1000]$} & 250 & {$[0,750]$} & 0.54 \\
\hline Patients with $>500 \mathrm{~mL}$ residual Urine volume, no. (\%) & 8 & (50) & 9 & $(56)$ & 0.73 \\
\hline \multicolumn{6}{|l|}{ Long-Term Medication, no. (\%) } \\
\hline Beta Blocker & 13 & (82) & 12 & (75) & 0.67 \\
\hline ACE Inhibitors/AT1 Blocker & 8 & (50) & 9 & (56) & 0.72 \\
\hline Diuretics & 4 & (25) & 5 & (31) & 0.69 \\
\hline \multicolumn{6}{|l|}{ Preoperative Laboratory } \\
\hline Hemoglobin, g/dL & 11.8 & {$[10.7,12.5]$} & 11.1 & {$[10.4,12.2]$} & 0.70 \\
\hline Haematocrit, \% & 35.7 & {$[32.5,38.3]$} & 33.2 & {$[31.9,37.4]$} & 0.67 \\
\hline Creatinine, $m g / d L$ & 7.5 & {$[5.5,8,7]$} & 8.3 & {$[5.5,9.8]$} & 0.47 \\
\hline CRP, $m g / d L$ & 0.2 & {$[0.1,0.5]$} & 0.2 & {$[0.1,0.7]$} & 0.64 \\
\hline
\end{tabular}

Summary statistics are presented as counts, percentages of patients, means \pm SD, and median [25th percentile, 75th percentile]. All $P$-values are for unpaired Student's $t$-tests, Mann-Whitney-U test or chi-square tests as appropriate. ASA American Society of Anesthesiologists physical status; ACE angiotensin converting enzyme; $A T 1$ angiotensin; CRP C-reactive protein

Table 2 Donor characteristics

\begin{tabular}{|c|c|c|c|c|c|}
\hline & $\begin{array}{l}\text { Mannitol } \\
(n=16)\end{array}$ & & $\begin{array}{l}\text { Placebo } \\
(n=16)\end{array}$ & & $p$-Value \\
\hline Age, yrs & 55 & (range 40,75 ) & 60 & (range 41,69 ) & 0.70 \\
\hline Sex & & & & & 0.47 \\
\hline Men, (\%) & 8 & (50) & 11 & (69) & \\
\hline Women, (\%) & 8 & (50) & 5 & (31) & \\
\hline \multicolumn{6}{|l|}{ Laboratory } \\
\hline Creatinine $m g / d L$ & 0.7 & {$[0.6,1.0]$} & 0.9 & {$[0.7,1.1]$} & 0.06 \\
\hline $\mathrm{BUN}, \mathrm{mg} / \mathrm{dL}$ & 25 & {$[14,42]$} & 19 & {$[17,46]$} & 0.83 \\
\hline Diuresis, $m L 24 h^{-1}$ & 2730 & {$[1860,4560]$} & 2800 & {$[2155,4540]$} & 0.73 \\
\hline Noradrenaline, $\mu \mathrm{g} \mathrm{kg}{ }^{-1} \mathrm{~min}^{-1}$ & 0.15 & {$[0.06,0.19]$} & 0.16 & {$[0.04,0.22]$} & 0.81 \\
\hline \multicolumn{6}{|l|}{ Duration of Ischaemia } \\
\hline Cold, $\min$ & 774 & {$[480,1071]$} & 768 & {$[543,1150]$} & 0.78 \\
\hline Warm, min & 45 & {$[35,53]$} & 44 & {$[30,58]$} & 0.91 \\
\hline
\end{tabular}


Table 3 Intraoperative parameters

\begin{tabular}{|c|c|c|c|c|c|}
\hline & $\begin{array}{l}\text { Mannitol } \\
(n=16)\end{array}$ & & $\begin{array}{l}\text { Placebo } \\
(n=16)\end{array}$ & & $p$-Value \\
\hline \multicolumn{6}{|l|}{ Duration } \\
\hline Anesthesia, hrs & 3.6 & {$[3.1,4.1]$} & 3.8 & {$[3.4,4.3]$} & 0.35 \\
\hline Surgery, hrs & 2.6 & {$[2.2,3.2]$} & 2.9 & {$[2.4,3.5]$} & 0.55 \\
\hline Arterial Clamp, min & 16 & {$[10,23]$} & 24 & {$[12,29]$} & 0.25 \\
\hline Venous Clamp, min & 22 & {$[16,25]$} & 20 & {$[15,25]$} & 0.47 \\
\hline \multicolumn{6}{|l|}{ Fluid \& Hemodynamics } \\
\hline Total Fluid, $m L$ & 1.870 & \pm 817 & 1.823 & \pm 558 & 0.85 \\
\hline Blood Loss, $m L$ & 200 & {$[100,588]$} & 175 & {$[0,375]$} & 0.49 \\
\hline MAP, TWA $\mathrm{mmHg}$ & 77 & {$[74,91]$} & 79 & {$[74,82]$} & 0.74 \\
\hline $\mathrm{SV}, \mathrm{mL}$ & 51 & {$[43,82]$} & 64 & {$[52,72]$} & 0.74 \\
\hline $\mathrm{CO}, \angle \mathrm{min}^{-1}$ & 3.1 & {$[2.5,5.0]$} & 4.3 & {$[2.9,4.7]$} & 0.97 \\
\hline $\mathrm{CVP}, \mathrm{mmHg}$ & 13 & \pm 4 & 12 & \pm 4 & 0.47 \\
\hline \multicolumn{6}{|l|}{ Anesthesia Variables } \\
\hline Propofol, mg & 190 & {$[123,200]$} & 200 & {$[90,230]$} & 0.92 \\
\hline Fentanyl, $\mu g$ & 650 & {$[500,750]$} & 550 & {$[400,800]$} & 0.92 \\
\hline et Sevoflurane TWA, \% & 1.3 & \pm 0.5 & 1.5 & \pm 0.3 & 0.36 \\
\hline $\mathrm{SpO}_{2}, \%$ & 99 & {$[98,99]$} & 98 & {$[96,99]$} & 0.15 \\
\hline Core, $\mathrm{T}^{\circ} \mathrm{C}$ & 36.3 & \pm 0.4 & 36.4 & \pm 0.5 & 0.32 \\
\hline \multicolumn{6}{|l|}{ Phenylephrine } \\
\hline No. of Patients, (\%) & 8 & $(50)$ & 11 & (69) & 0.78 \\
\hline Cumulative Dose, $m g$ & 0.02 & {$[0.0,0.4]$} & 0.08 & {$[0.0,0.19]$} & 0.99 \\
\hline \multicolumn{6}{|l|}{ Noradrenaline } \\
\hline No. of Patients, (\%) & 5 & $(32)$ & 5 & (32) & 1.00 \\
\hline Cumulative Dose, $m g$ & 0.14 & {$[0.00,0.29]$} & 0.11 & {$[0.00,0.20]$} & 0.86 \\
\hline \multicolumn{6}{|c|}{ Central Venous Blood Gas Analysis } \\
\hline $\mathrm{pH}$ & 7.36 & \pm 0.1 & 7.37 & \pm 0.1 & 0.40 \\
\hline $\mathrm{pCO}_{2}, \mathrm{mmHg}$ & 44 & \pm 7 & 46 & \pm 7 & 0.34 \\
\hline $\mathrm{pO}_{2}, \mathrm{mmHg}$ & 49 & {$[42 ; 56]$} & 52 & {$[46 ; 56]$} & 0.38 \\
\hline $\mathrm{Hb}, g / d L$ & 9.7 & \pm 1.4 & 9.6 & \pm 1.3 & 0.62 \\
\hline $\mathrm{Na}^{+}, \mathrm{mmol} / \mathrm{L}$ & 136 & \pm 3 & 138 & \pm 2 & 0.04 \\
\hline $\mathrm{K}^{+}, \mathrm{mmol} / \mathrm{L}$ & 4.7 & \pm 0.7 & 4.7 & \pm 0.4 & 0.93 \\
\hline Lactate, $\mathrm{mmol} / \mathrm{L}$ & 0.8 & \pm 0.2 & 0.8 & \pm 0.3 & 0.49 \\
\hline
\end{tabular}

Summary characteristics of intraoperative measurements presented as means \pm SD or medians [25th percentile, 75th percentile]. All $P$-values are for unpaired Student's $t$-tests or Mann-Whitney-U tests as appropriate. MAP mean arterial pressure; TWA time weighted average; SV stroke volume; FTC corrected flow time; CO cardiac output, $\mathrm{CVP}$ central venous pressure, $\mathrm{pCO}_{2}$ partial pressure of carbon dioxide; $\mathrm{pO}_{2}$ partial pressure of oxygen; $\mathrm{BE}$ base excess; $\mathrm{Hb}$ hemoglobin

inflammation and cardiovascular disease [27, 28]. Additionally, sTie to has been shown to be correlated to VEGF which is dramatically upregulated under hypoxic circumstances [29]. Though, the exact mechanism of sTie2 in ischemia is not well understood it plays an important role in the regulation of angiogenesis and vascular inflammation. In our study Tie2 concentrations $24 \mathrm{~h}$ after transplantation were significantly higher in the placebo group. But, after taking pre transplantation concentrations into account by comparing the changes of concentrationen over time Tie2 was no longer significantly different between study groups.

KIM1, NGAL and IGFBP7 are specific biomarkers to detect renal tubular injury [30, 31]. KIM1 increased significantly less in the mannitol group over $24 \mathrm{~h}$ after graft reperfusion. However, there were no differences in NGAL and IGFBP7 in both groups over time. As concentrations of these three BM measured $24 \mathrm{~h}$ after reperfusion did not differ significantly 
Table 4 Postoperative parameters within $24 \mathrm{~h}$

\begin{tabular}{llllll}
\hline & $\begin{array}{l}\text { Mannitol } \\
(n=16)\end{array}$ & \multicolumn{2}{l}{$\begin{array}{l}\text { Placebo } \\
(n=16)\end{array}$} & $p$-Value \\
\hline $\mathrm{K}^{+}, \mathrm{mmol} / \mathrm{L}$ & 4.6 & \pm 0.6 & 4.7 & \pm 1.4 & 0.284 \\
Urinary Output, $\mathrm{mL}$ & 1600 & {$[690,2750]$} & 1125 & {$[550,2375]$} & 0.678 \\
Creatinine, $\mathrm{mgdL}$ & 5.1 & \pm 2.5 & 5.7 & \pm 2.1 & 0.384 \\
BUN, $\mathrm{mg} / \mathrm{dL}$ & 34.7 & \pm 11.9 & 33.9 & \pm 12.6 & 0.702 \\
GFR, $\mathrm{mL} \mathrm{min} \mathrm{min}^{-1} 1.73 \mathrm{~m}^{-2}$ & 11.8 & \pm 7.0 & 10.3 & \pm 5.4 & 0.436 \\
\hline
\end{tabular}

Summary characteristics of postoperative measurements $24 \mathrm{~h}$ after graft reperfusion. Data are presented as means \pm SD or medians [25th percentile, 75th percentile]. All $P$-values are for a mixed linear model adjusted for the correlated nature of paired donor kidneys. BUN blood urea nitrogen; GFR glomerular filtration rate

between both groups, a protective effect of mannitol on tubular damages remains still questionable.

$\mathrm{I} / \mathrm{R}$ injury is associated with inflammation and plays a crucial role in tissue damage and immune cell recruitment. One important protein is VCAM1, which is triggered by cytokines leading to endothelial cell-leukocytes adhesion and trans-endothelial migration into inflamed tissue. In vitro studies confirmed VCAM1 as a major contributor for leukocyte recruitment and consequently tissue damage during $I / R$ injury [32]. Upregulation of VCAM1 correlates with structural tubular damage and fibrotic changes [33]. In our study population VCAM1 significantly increased over time in the mannitol group but no difference could be detected in VCAM1 concentrations $24 \mathrm{~h}$ after graft reperfusion.

Endostatin is the c-terminal fragment of collagen XVII, which is expressed in the membranes of glomerular, tubular epithelium, and vascular endothelium cells [34,
35]. Endostatin increases significantly in patients with AKI [36]. In our study population there was a decrease of Endostatin $24 \mathrm{~h}$ after transplantation, however there was no difference between both study groups.

IL18 is a proinflammatory cytokine and is a mediator and biomarker of ischaemic tissue damage [37]. Tubular epithelial cells express NGAL in response to tubulointerstitial cell injury which is mainly released by leucocytes, the loop of Henle and the collecting ducts [38]. NGAL is significantly higher in patients with delayed graft dysfunction after transplantation. Cystatin $\mathrm{C}$ is a promising serum BM for all-cause AKI with a pooled sensitivity, specificity and AUROC of $0.82,0.82$ and 0.89 , respectively [39]. FGF23 is an early predictor and fast responding biomarker for AKI [40] and is significantly higher in patients developing AKI after cardiac surgery and ICU patients [41].

There are few BM which display statistically significant differences in concentration changes over time or in concentrations $24 \mathrm{~h}$ post transplantation but the BM panel as a whole provides little evidence for differences in the study groups. Additionally, we measured routine clinical parameters such as creatinine, urinary output and potassium. There was no difference in those parameters, which further underlines the lack of efficacy of mannitol in patients undergoing deceased renal transplantation.

Adequate intraoperative hydration during renal transplantation is associated with a lower incidence of delayed graft function $[42,43]$. Thus, the strength of our study is esophageal Doppler guided fluid management and stroke volume optimization in all of our patients.

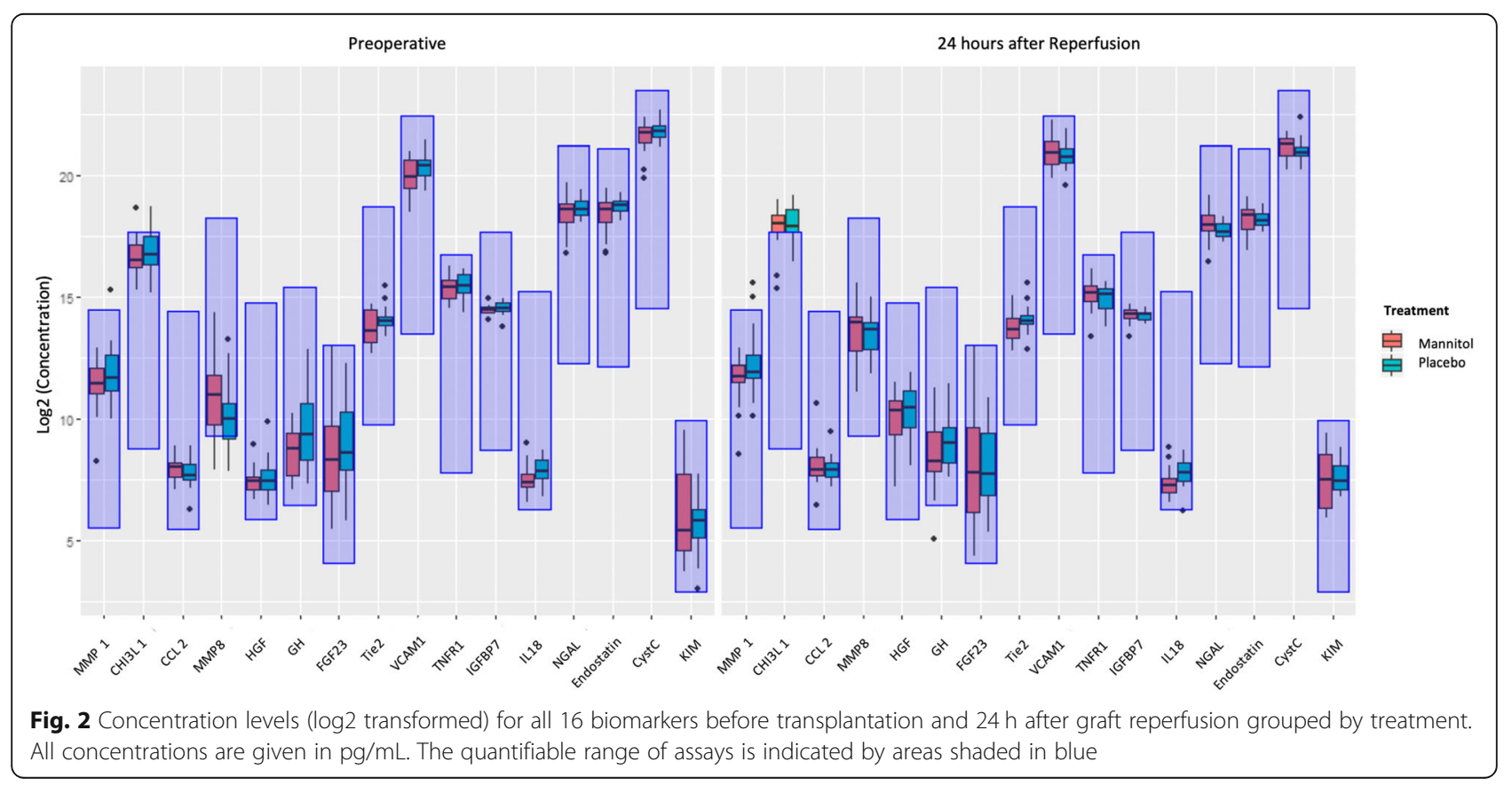


Table 5 Biology-derived Biomarkers

\begin{tabular}{llll}
\hline & $\begin{array}{l}\text { Mannitol } \\
(n=16)\end{array}$ & $\begin{array}{l}\text { Placebo } \\
(n=16)\end{array}$ & $\begin{array}{c}p \text {-value } \\
\text { MMP1 }\end{array}$ \\
CHI3L1 & $2492[3040,4910]$ & $3828[3299,6556]$ & 0.360 \\
CCL2 & $244[208,314]$ & $290,668 \pm 43,544$ & 0.882 \\
MMP8 & $17,414 \pm 11,898$ & $240[196,303]$ & 0.711 \\
HGF & $1488 \pm 847$ & $13,001 \pm 7340$ & 0.126 \\
GH & $286[189,598]$ & $1736 \pm 1124$ & 0.800 \\
FGF23 & $170[67,1673]$ & $511[292,981]$ & 0.387 \\
Tie2 & $12,563[9594,18,103]$ & $215[116,722]$ & 0.183 \\
VCAM1 & $2,057,315[1,483,384,3,106,136]$ & $16,357[14,596,20,411]$ & 0.011 \\
TNFR1 & $36,465 \pm 14,344$ & $1,741,057[1,422,526,2,331,264]$ & 0.354 \\
IGFBP7 & $19,960 \pm 4097$ & $32,838 \pm 10,274$ & 0.272 \\
IL18 & $158[130,208]$ & $19,385 \pm 2886$ & 0.556 \\
NGAL & $252,684[202,155,340,047]$ & $221[171,304]$ & 0.202 \\
Endostatin & $314,261 \pm 123,046$ & $206,354[182,217,273,962]$ & 0.091 \\
CystC & $2,405,546[1,716,719,2,976,273]$ & $307,918 \pm 74,018$ & 0.981 \\
KIM1 & $249 \pm 197$ & $2,023,359[1,794,789,2,449,441]$ & 0.994 \\
\hline Tesing & $227 \pm 108$ & 0.624 \\
\hline
\end{tabular}

Testing for differences in BM concentrations $24 \mathrm{~h}$ after transplantation. Data are presented as means \pm SD or medians [25th percentile, 75 th percentile]. All concentrations are given in $\mathrm{pg} / \mathrm{mL}$ A mixed linear model adjusted for paired donor kidneys was applied

Therefore, we can exclude differences in fluid volume status as a potential confounder. Additionally, protein measurements were carried out strictly according to protocol - samples were stored at $-80^{\circ} \mathrm{C}$ and never thawn prior to measurements. Rigorous $\mathrm{QC}$ control according to FDA and EMA guidelines ensure accurate and reproducible results.

Since the effect of manntol begins within minutes after administrationit seems unlikely that a single dose of mannitol might improve renal function in the long-term. Therefore, we focused on the effect within the $24 \mathrm{~h}$ after graft reperfusion evaluated with our set of $16 \mathrm{BM}$. Because of our small sample size we were not able to draw any conclusions regarding postoperativ long-term renal graft function e.g. requirement of dialysis. Furthermore, we did not assess our biomarkers in healthy patients without any renal dysfunction which might have provided valuable addintional physiological renal background information.

\section{Conclusion}

Few of the measured BM showed statistically differences in concentrations $24 \mathrm{~h}$ after transplantation between the mannitol and the placebo group as well as differences in concentration changes over time. Nevertheless the whole BM panel displayed limited evidence for the supposedly renoprotective effect of mannitol in patients exposed to reperfusion injury after deceased renal transplantation. We thus do not support the routine use of mannitol during graft reperfusion. This study awaits confirmation in an outcome trial.

\section{Supplementary information}

Supplementary information accompanies this paper at https://doi.org/10. 1186/s12882-020-01961-z.

\section{Additional file 1.}

\section{Abbreviations}

MMP1: Matrix metalloproteinase-9; CCL2: Chemokine (C-C motif) ligand-2; MMP8: Matrix metalloproteinase-8; GH: Growth hormone; FGF23: Fibroblast growth factor-23; Tie2: Tyrosine Kinase-2; IGFBP7: Insulin Like Growth Factor Binding Protein-7; Endostatin: Endostatin; KIM1: Kidney Injury Molecule-1;

CHI3L1: Chitinase-3-like protein-1; HGF: Hepatocyte growth factor;

VCAM1: Vascular cell adhesion protein-1; TNFR1: Tumor necrosis factor receptor-1; IL18: Interleukin-18; NGAL: Neutrophil gelatinase-associated lipocalin; CystC: Cystatin C

\section{Acknowledgments}

Not applicable.

\section{Authors' contributions}

All authors have read and approved the manuscript. C.R.: data acquisition, writing and preparation of the manuscript. K.H.: proteomics measurements, contributed to data quality control and contributed to writing of the manuscript. S.S.: study protocol, data acquisition. M.F.: data acquisition, writing and revision of the manuscript. E.F.: study protocol, writing and preparation of the manuscript. A.K.: data processing and analysis and contributed to writing of the manuscript. B.K.: study protocol, writing and preparation of the manuscript. 


\section{Funding}

This work was supported by the Medical University of Vienna.

\section{Availability of data and materials}

The datasets used and/or analyzed during the current study are available from the corresponding author on reasonable request. Corresponding author: edith.fleischmann@meduniwien.ac.at

\section{Ethics approval and consent to participate}

The trial was approved by the local ethics committee of the Medical University of Vienna in 2014 (Chairman: J. Zezula, MD) (EK 2021/2014) and was registered at ClinicalTrials.gov (NCT02705573) and EudraCT (2014005391-29) and conducted according to the Declaration of Helsinki and Good Clinical Practice. Written informed consent was obtained from all patients before they were enrolled into the study.

\section{Consent for publication}

Not applicable.

\section{Competing interests}

The authors declare no competing interests.

\section{Author details}

${ }^{1}$ Department of Anaesthesia, Intensive Care Medicine and Pain Medicine, Medical University of Vienna, Spitalgasse 23, 1090 Vienna, Austria. ${ }^{2}$ Clinical Department of Nephrology and Dialysis, Medical University of Vienna, Vienna, Austria.

\section{Received: 14 February 2020 Accepted: 17 July 2020}

Published online: 28 July 2020

\section{References}

1. Kaballo MA, Canney M, O'Kelly P, Williams Y, O'Seaghdha CM, Conlon PJ. A comparative analysis of survival of patients on dialysis and after kidney transplantation. Clin Kidney J. 2018;11:389-93.

2. Rabbat CG, Thorpe KE, Russell JD, Churchill DN. Comparison of mortality risk for dialysis patients and cadaveric first renal transplant recipients in Ontario, Canada. J Am Soc Nephrol. 2000;11:917-22.

3. Ponticelli C. Ischaemia-reperfusion injury: a major protagonist in kidney transplantation. Nephrol Dial Transplant. 2014;29:1134-40.

4. Kezić A, Stajic N, Thaiss F. Innate immune response in kidney ischemia/ reperfusion injury: potential target for therapy. J Immunol Res. 2017

5. Cosentino M, Breda A, Sanguedolce F, et al. The use of mannitol in partial and live donor nephrectomy: an international survey. World J Urol. 2013;31: 977-82.

6. Lugo-Baruqui JA, Ayyathurai R, Sriram A, Pragatheeshwar KD. Use of Mannitol for ischemia reperfusion injury in kidney transplant and partial nephrectomies-review of literature. Curr Urol Rep. 2019;20.

7. Bragadottir G, Redfors B, Ricksten SE. Mannitol increases renal blood flow and maintains filtration fraction and oxygenation in postoperative acute kidney injury: a prospective interventional study. Crit Care. 2012;17.

8. Thomas ME, Blaine C, Dawnay A, et al. The definition of acute kidney injury and its use in practice. Kidney Int Elsevier Masson SAS. 2015;87:62-73.

9. Parikh $C R$, Jani A, Mishra J, et al. Urine NGAL and IL-18 are predictive biomarkers for delayed graft function following kidney transplantation. Am J Transplant. 2006;6:1639-45.

10. Mayer P, Mayer B, Mayer G. Systems biology building a useful model from multiple markers and profiles. Nephrol Dial Transplant. 2012;27:3995-4002.

11. Mayer G, Heerspink HJL, Aschauer C, et al. Systems biology-derived biomarkers to predict progression of renal function decline in type 2 diabetes. Diabetes Care. 2017;40:391-7.

12. Van Timmeren MM, Vaidya VS, Van Ree RM, et al. High urinary excretion of kidney injury molecule-1 is an independent predictor of graft loss in renal transplant recipients. Transplantation. 2007;84:1625-30.

13. Einecke G, Sis B, Reeve J, et al. Antibody-mediated microcirculation injury is the major cause of late kidney transplant failure. Am J Transplant. 2009;9: 2520-31.

14. Han WK, Bailly V, Abichandani R, Thadhani R, Bonventre JV. Kidney injury Molecule-1 (KIM-1): a novel biomarker for human renal proximal tubule injury. Kidney Int. 2002;62:237-44.
15. Lohkamp LN, Öllinger R, Chatzigeorgiou A, Illigens BMW, Siepmann T. Intraoperative biomarkers in renal transplantation. Nephrology. 2016;21:18899.

16. Malhotra R, Siew ED. Biomarkers for the early detection and prognosis of acute kidney injury. Clin J Am Soc Nephrol. 2017;6:149-73.

17. Feldheiser A, Conroy P, Bonomo T, Cox B, Ruiz Garces T, Spies C. Development and feasibility study of an algorithm for intraoperative goaldirected haemodynamic management in noncardiac surgery. J Int Med Res. 2012;40:1227-41.

18. Moledina DG, Hall IE, Thiessen-Philbrook H, et al. Performance of serum Creatinine and kidney injury biomarkers for diagnosing histologic acute tubular injury. Am J Kidney Dis. 2017;70.

19. Lugo-Baruqui JA, Ayyathurai R, Sriram A, Pragatheeshwar KD. Use of Mannitol for ischemia reperfusion injury in kidney transplant and partial nephrectomies - review of literature. Curr Urol Rep. 2019;26.

20. Green RD, Boyer DA, Halasz N, Collins GM. Pharmacological protection of rabbit kidneys from normothermic ischemia. Transplantation. 1979;28:131-4.

21. Van Valenberg PL, Hoitsma AJ, Tiggeler RGWL, Berden JHM, Van Lier HJJ, Koene RAP. Mannitol as an indispensable constituent of an intraoperative hydration protocol for the prevention of acute renal failure after renal cadaveric transplantation. Transplantation. 1987:44:784-8.

22. Weimar W, Geerlings W, Bijnen A, et al. A controlled study on the effect of mannitol on immediate renal function after cadaver donor kidney transplantation. Transplantation. 1983;35:99-101.

23. Tiggeler RGWL, Berden JHM, Hoitsma AJ, Koene RAP. Prevention of acute tubular necrosis in cadaveric kidney transplantation by the combined use of mannitol and moderate hydration. Ann Surg. 1985;201:246-51.

24. Hanif F, Macrae AN, Littlejohn MG, Clancy MJ, Murio E. Outcome of renal transplantation with and without intra-operative diuretics. Int J Surg. 2011;9: 460-3.

25. Raju DL, Grover VK, Shoker A. Limitations of glomerular filtration rate equations in the renal transplant patient. Clin Transpl. 2005;19:259-68.

26. Singh $\mathrm{H}$, Hansen TM, Patel N, Brindle NPJ. The molecular balance between receptor tyrosine kinases Tie1 and Tie2 is dynamically controlled by VEGF and TNFa and regulates angiopoietin signalling. PLoS One. 2012;7.

27. Chung NAY, Makin AJ, Lip GYH. Measurement of the soluble angiopoietin receptor tie-2 in patients with coronary artery disease: development and application of an immunoassay. Eur J Clin Investig. 2003;33:529-35.

28. Koutroubakis IE, Xidakis C, Karmiris K, Sfiridaki A, Kandidaki E, Kouroumalis EA. Potential role of soluble angiopoietin-2 and Tie-2 in patients with inflammatory bowel disease. Eur J Clin Investig. 2006;36:127-32.

29. Olsson AK, Dimberg A, Kreuger J, Claesson-Welsh L. VEGF receptor signalling - In control of vascular function. Nat Rev Mol Cell Biol. 2006;7: 359-371d.

30. Bolignano D, Donato V, Coppolino G, et al. Neutrophil Gelatinase-associated Lipocalin (NGAL) as a marker of kidney damage. Am J Kidney Dis. 2008;52: 595-605.

31. Fan W, Ankawi G, Zhang J, et al. Current understanding and future directions in the application of TIMP-2 and IGFBP7 in AKI clinical practice. Clin Chem Lab Med. 2019;57:567-76.

32. Cassie S, Masterson MF, Polukoshko A, Viskovic MM, Tibbles LA. Ischemia/ reperfusion induces the recruitment of leukocytes from whole blood under flow conditions. Free Radic Biol Med. 2004;36:1102-11.

33. Mrowka C, Sieberth HG. Circulating adhesion molecules ICAM-1, VCAM-1 and E-selectin in systemic vasculitis : marked differences between Wegener's granulomatosis and systemic lupus erythematosus. Clin Investig. 1994;72:762-8

34. Tomono Y, Naito I, Ando K, et al. Epitope-defined monoclonal antibodies against Multiplexin collagens demonstrate that type XV and XVIII collagens are expressed in specialized basement membranes. Cell Struct Funct. 2002;27:9-20.

35. Marneros AG, Olsen BR. Physiological role of collagen XVIII and endostatin. FASEB J. 2005

36. Jia HM, Zheng $Y$, Huang LF, et al. Derivation and validation of plasma endostatin for predicting renal recovery from acute kidney injury: a prospective validation study. Critical Care. 2018;22:305.

37. Malyszko J, Lukaszyk E, Glowinska I, Durlik M. Biomarkers of delayed graft function as a form of acute kidney injury in kidney transplantation. Sci Rep. 2015;15.

38. Wasung ME, Chawla LS, Madero M. Biomarkers of renal function, which and when? Clin Chim Acta [Internet] Elsevier BV 2015:438:350-7. 
39. Yong Z, Pei X, Zhu B, Yuan H, Zhao W. Predictive value of serum cystatin C for acute kidney injury in adults: a meta-analysis of prospective cohort trials. Sci Rep [Internet] Nature Publishing Group. 2017;7:1-11.

40. Rygasiewicz K, Hryszko T, Siemiatkowski A, Brzosko S, Rydzewska-Rosolowska A, Naumnik B. C-terminal and intact FGF23 in critical illness and their associations with acute kidney injury and in-hospital mortality. Cytokine. 2018;103:15-9

41. Christov M, Waikar SS, Pereira RC, et al. Plasma FGF23 levels increase rapidly after acute kidney injury. Kidney Int. 2013;84:776-85.

42. Collange $\mathrm{O}$, Jazaerli L, Lejay A, et al. Intraoperative Pleth variability index is linked to delayed graft function after kidney transplantation. Transplant Proc. 2016;48:2615-21.

43. Othman MM, Ismael AZ, Hammouda GE. The impact of timing of maximal crystalloid hydration on early graft function during kidney transplantation. Anesth Analg. 2010;110:1440-6

\section{Publisher's Note}

Springer Nature remains neutral with regard to jurisdictional claims in published maps and institutional affiliations.

Ready to submit your research? Choose BMC and benefit from:

- fast, convenient online submission

- thorough peer review by experienced researchers in your field

- rapid publication on acceptance

- support for research data, including large and complex data types

- gold Open Access which fosters wider collaboration and increased citations

- maximum visibility for your research: over $100 \mathrm{M}$ website views per year

At $\mathrm{BMC}$, research is always in progress.

Learn more biomedcentral.com/submissions 